\title{
MEMS ENTREPRENEURIAL PERSPECTIVES
}

\author{
Kurt Petersen, PhD \\ Band of Angels, Menlo Park, California, USA
}

\begin{abstract}
Being involved in the founding of a successful start-up company is one of the most exhilarating and satisfying experiences a person can have. Inventing, developing, and bringing to market a new product or a new technology, which provides a service that thousands or even millions of people will actually PAY to enjoy, is almost mind numbing. I have started six companies. TDI, NovaSensor, and Verreon were eventually acquired. Cepheid did an IPO in 2000. SiTime and Profusa are still private, but both have the potential to do an IPO. Looking back, you realize how luck can also be involved in such successes. To a large extent, people do make their own luck, but large success stories are often dependent on a substantial degree of good fortune. This paper is intended to discuss various stories of some of my start-up companies, how we overcame crucial hurdles, start-up advice, and how today's entrepreneurs might help themselves "make their own luck".
\end{abstract}

\section{THE TEAM}

When investors evaluate new start-up companies for potential funding, the first thing they consider is "the team". Ideally, they look for experienced, been-there-done-that people, who have had previous involvement with successful start-up companies. This experienced team is somewhat more crucial when a (rare) Series A financing of $\$ 5 \mathrm{M}$ to $\$ 10 \mathrm{M}$ is involved. Investors today are much more risk averse than those hey-days around 2000 and again around 2007. It is extremely difficult, in 2014, for hardware startups to obtain Series A investments. Today, hard-ware start-ups are often seed-funded by angel investors, such as the Band of Angels in Silicon Valley. In this case, teams can be much more junior, as long as there is an understanding among the founders that more senior, seasoned executives may replace founders in CEO and President roles at a later date. Founders, please do not be offended by this possibility. It is important to realize that all successful companies require a wide variety of necessary skills, from inventors, to engineers, to operations people, to marketing and sales people, to financial experts, to skilled business people. It is the rare founder who is expert in 2 or more of such skills.

So, put a lot of thought and energy into the design of the team. As we founded Verreon, we specifically designed the entire company to be acquired by Qualcomm. Since Qualcomm is so obsessed with IP, we hired a patent agent who was experienced with MEMS. And we also hired an operations expert who would bring more to the team than just a bunch of inventors. Qualcomm loved our team and the acquisition happened within 9 months of engaging with them. After this team was eventually acquired by Qualcomm, the yearly Qualcomm employee ranking system rated the Verreon employees at the very top of their engineering population.

When we founded Cepheid, one of the first tasks I undertook was the recruitment of a biomedical-experienced CEO, from my network. All the other founders were technical people, one biologist, one micro-fluidics engineer, one electrical engineer, and one mechanical engineer. Very shortly after getting funding, we hired an experienced industrial design engineer. It's always the Team that makes a company successful.

By the way, it is your network which makes it possible to connect with potential partners and potential employees for your start-up. Always look for any occasion to enhance your network. The wider your network, the more opportunities you will have for potential employees and/or partners and/or new prospective startup companies. It is never too early to start putting your network together and you never stop expanding your network.

Besides the composition of the team, one of the biggest issues you will deal with when organizing a new start-up company is the distribution of stock. Be as fair and as generous as you can. But, please do not waste countless hours quibbling about a few percentage points here and there, which I have seen too many times. Keep in mind that business experience is just as important, if not more so, than engineers and inventors. It is also critical, of course, to set aside stock for additional potential employees.

\section{THE VISION}

It is critical that your company have a "Vision", which you can articulate to anyone within 60 seconds. A simple technical idea is critical, of course, but it is not enough for a truly transformative new company. The Vision must capture the longterm goals of the company and why the company's products will transform the intended marketplace. At Cepheid, we had the vision of transforming the diagnostics industry by providing rapid DNA diagnostics totally automatically in less than an hour. At SiTime, we had the vision of creating a timing-chip company, where customers who bought SiTime timing chips, would not have to buy a quartz crystal, because the MEMS replacement for the quartz crystal was already inside the same package with the timing chip. At Profusa, we have the vision of finally solving the problem of implantable chemical sensors.

Technical ideas can come from many different sources. Obviously, the most important issue is that the idea must become a product which people will want to purchase. Less obvious is that the product(s) or product line should also have the capability to grow dramatically in customer demand. That is, try not to be a one-trick pony. At NovaSensor, we wanted to create a "MEMS" company, but we did not have a specific first product in mind. Our funded sponsor, Schlumberger, had contracted with us to develop three very high performance pressure sensors, but no one knew how long it would take to get these very advanced devices into production, actually generating revenue. Fortunately, within a few months of starting NovaSensor, a company approached us to manufacture disposable blood pressure sensor chips for them because their current supplier was unreliable. So, our first product was the second source to replace another supplier. The first shipment (50K of these disposable pressure sensor chips) was made when the company was only about 6 months old. This was actually NovaSensor's financially most successful product for several years and set the company up for acquisition 4 years later. Even if the first product is not the ultimate best product, the ability to be in production as soon as possible is incredibly important, because you will have sales revenue coming in the door.

In 1996, two new ideas started Cepheid; the ability to perform rapid PCR for diagnostic identification of DNA or RNA segments, and automatic sample preparation (extracting and purifying DNA or RNA from a raw biological sample). When these two capabilities are completely developed, a disposable cartridge could perform a complete diagnostic assay totally inside the cartridge. However, creating the complete diagnostic platform, as well as the 
PCR-based assays, would require MANY years of development and FDA approvals, while not generating any revenues. So, we developed the rapid PCR capability first and built a life sciences research product to start (which does not require FDA approval). First shipments of this relatively simple product occurred 3 years after founding Cepheid. Sales of the SmartCycler helped to subsidize development of the fully integrated product, the GeneXpert, which came on the market $2 \frac{1}{2}$ years later. Again, a not-perfect first product came to market first and subsidized the product which was the ultimate goal of the company.

At SiTime, the process for the creation of the MEMS-first oscillators was actually developed at Robert Bosch to reduce the packaging complexity of gyroscopes. When it was discovered that a resonator inside the epi-sealed cavity could exhibit a $\mathrm{Q}$ of over $100 \mathrm{~K}$, the idea for a MEMS-based oscillator evolved. When the idea was developed to compensate the inherent temperature drift of these single crystal silicon resonators using circuitry, the basic concept was in place to create a product and a company to compete with the quartz crystal. The first $100 \mathrm{~K}$ parts were shipped to a customer within 32 months after receiving funding. However, it took another 5 years to demonstrate MEMS oscillators which were better than quartz in every way measurable, cost, noise, temperature performance, size, power, and reliability. The company is now poised to dominate the timing marketplace.

\section{THE MARKET}

Clearly the potential market for your device must be huge; multiple $\$ 100 \mathrm{M}$, preferably over \$1B. If it is not huge, investors will not write their checks. Why does the market need to be so large? Simple math. High risk investors, like venture capitalists and angels, expect to return at least $20 \%$ /year on their investments. If it takes $\$ 50 \mathrm{M}$ and 4 years to bring your idea into volume production, and you are fortunate enough to capture a very optimistic market share of $20 \%$ in another 2 years, this is $\$ 20 \mathrm{M} /$ year in sales for a market size of $\$ 100 \mathrm{M}$. If you exit after 6 years, the investors need to return $\$ 150 \mathrm{M}$, more than the entire size of the market! In this scenario, it will be impossible for the investors to make a reasonable return.

Less obvious is the fact that the founders have to anticipate what customers will want, not today or tomorrow, but 5 or more years from today, because that is how long it will take to bring the new idea into real production. Convincing investors that your idea will be wanted by millions of people, 5 years or more from now, can be a challenge.

We had this problem big-time at Cepheid. In the late 90's, MANY people were doing microfluidics. At the time, most microfluidic companies (Caliper, ACLARA, for example), were targeting drug development markets and applications, requiring thousands to millions of very small fluidic samples (nano-liters to pico-liters). Cepheid was somewhat of an outlier, targeting unproven diagnostic applications with milli-liter volumes. I'm pretty sure that investors thought nano-liters were sexier than milliliters. However, Cepheid was actually targeting an enormous market, which was being made possible by the huge progress in DNA sequencing going on at the time. Cepheid was founded in 1996. The first draft of the human genome was not published until 2000. Since then, virtually every organism has now been sequenced. How is this wealth of new information being used? It has revolutionized the field of molecular diagnostics, exactly where Cepheid is positioned as the leader. While not the case in 1996, molecular diagnostics today is a multi-billion dollar industry and is the fastest growing field in medical diagnostics.

Over 12 billion quartz crystal oscillators are shipped to the world's electronic companies every year. It is a $\$ 5 \mathrm{~B}+$ market.
Yet, quartz is a terrible, old-fashioned technology with inefficient production, high failure rates, and no possibility of integration with circuitry. So, when Markus Lutz, from Robert Bosch showed me his MEMS oscillator and how it could be controlled to compete with quartz crystals, I immediately began working on a business plan for a new company, SiTime. We had no trouble getting funding, because the market is enormous. However, competing with the quartz incumbent has been no easy task. While SiTime's oscillators are better than quartz in every way (as mentioned above), convincing the market to abandon a 50 year-old standard technology which only costs about 25 cents, has been challenging.

\section{THE DEMO}

While there are clearly exceptions, today it is basically not possible to generate serious interest from potential investors, without a significant demonstration of the technology and product. (BTW, venture capital folks are always "very interested" and polite and seldom to never say, "no, we are not interested". But getting a check from them is a different matter.) To maximize acceptance, the demonstration should be as complete as possible. When Cepheid was founded, we had demonstrated virtually nothing. However, I would be embarrassed to give the 1997 Cepheid presentation to today's much more sophisticated, selective, and risk averse, potential investors. Demonstrations should be focused around a targeted product, with the packaging and software to fully illustrate the advantages of the product. The importance of a demo in today's financing environment cannot be overestimated. It engages the audience, it proves the device can be built, it clarifies the use case, and it gives them more confidence that full scale production may not be that far away and may not be too difficult.

\section{INTELLECTUAL PROPERTY}

For hardware start-ups, there cannot be anything more important that IP. Investors will expect an extensive and comprehensive IP plan, and even filed provisionals or patents. They will review your patents and patent applications. They may even have experts evaluate your patents. Depending on the Vision and the Idea, investors may want to see a legal opinion on the company's Freedom to Operate (FTO). Basically, they are hoping to reduce the risk of competitors damaging the value of your company and the value of their investment, as well as evaluating the potential for future lawsuits. Work with experienced patent attorneys to put your portfolio together.

\section{EARLY FUNDING}

Hardware start-ups can require a lot of capital (maybe even as high as $\$ 100 \mathrm{M}$ ) and long periods of time (I always tell potential employees "at least 7 years") to become a convincing, moneymaking success. Investors' expectations today, even for early seed financing, is extremely high, especially for hardware companies (as opposed to software/internet, which we are not considering here). More and more early stage start-ups today are relying on small amounts of angel financing, as much government contracts they can get, and partnerships with large companies; then working very frugally to get the product close to volume production and getting interested potential customers. Funding from government agencies, such as DARPA and NIH, can be incredibly important today for getting a new company off the ground. At Profusa, which is developing an entirely new class of implantable chemical sensors, the company survived its first 4 years on small amounts of money from friends and family and small DARPA and NIH grants. Eventually these small DARPA and NIH grants became large DARPA and NIH grants. There are two other huge benefits to such grants. First, they add a huge degree of validation for future 
investors, and secondly, they are a form of non-dilutive funding, which is very advantageous to equity investors, like angels and VCs. After nearly 5 years of small scale funding, but a back-log of over $\$ 7 \mathrm{M}$ in government grants, Profusa raised a $\$ 1 \mathrm{M}$ angel round, then a \$3.5M Series A round, all from HNW individual investors.

At Cepheid, a key part of our pitch for our Series A was, "we have a license agreement for a key patent from Lawrence Livermore Labs, and we have a \$3M contract from the US Army". The grant was THE deciding factor for many Series A investors.

However, there is another side to government money of which you need to be cognizant. I have a friend who calls government money "cocaine". Without discipline, the company can easily turn into "an SBIR factory," relying on new BAAs to get more money, which then distracts the company from its real, commercial product. At Cepheid, as well as at Profusa, we had a firm rule that any government money would not distract us from the real product and, in fact, would only be spent on product development, or we would not take the money.

\section{CHAMPIONS}

Your chances of getting funding increases dramatically when you have real outside "champions" for your technology/product or company. Investors rely heavily on such champions to vet your company and to assess your likelihood for financial success. At Cepheid, we had several eminent doctors on our Technical Advisory Board (TAB). One was Nobel Prize winner, Stanley Falkow. Another was David Relman, president of the Infectious Disease Society of America. At SiTime, we were lucky to get a huge endorsement from John Vig, the reputed expert on quartz crystal oscillators. John joined the SiTime TAB. Again, use your network to attract these folks. They can be incredibly influential.

\section{INCORPORATING THE COMPANY}

Seemingly a mundane and obvious procedure, incorporating the company properly is critical. An improper incorporation can have severe consequences later in the history of the company. Both experienced investors as well as potential acquirers, who might like the company, have stringent legal requirements on investments/acquisitions. Don't go to your cousin's friend who is an attorney, for legal work. Talk to veteran entrepreneurs (your network!) and get recommendations on credible law-firms, experienced with the unique requirements of high-tech start-ups. I have lived through one such situation. We got an acquisition interest from a larger company and began negotiations. However, the legal structure of the start-up was a mess. It took an enormous effort, and almost collapsed the deal, to resolve all the issues.

\section{GETTING REAL MONEY}

Timing for VC funding is critical. We closed our Series B and C rounds for Cepheid, partly funded by VCs, in 1998 and 2000 , during the up-slope of the dot-com boom. We closed our Series A, B, and C rounds for SiTime in 2004, 2006, and 2007 just on the up-slope of the financial recovery after the crash of 2000. Only one of my six companies, SiTime, was fully funded with "traditional" venture capital money. It is supremely difficult to raise traditional $\mathrm{VC}$ funding in a down cycle for the economy and for several years later. It is important that you consider the existing economic conditions related to the timing of the founding of your company, because this will impact how you get funding.

One of the most important moves of my career was when my co-founder, Bill McMillan, and I recruited Tom Gutshall and asked him to be CEO of Cepheid. Tom had been a senior VP at Syntex and president of their diagnostic division, Syva. He had just headed the sale of Syntex to Roche for $\$ 5.3 \mathrm{~B}$, so he completely understood the biomedical industry. Critical for Cepheid is that Tom had an amazing "rolodex". His list of high net worth (HNW) individuals was phenomenal. We raised our Series A, $\$ 3.2 \mathrm{M}$, mostly from Tom's rolodex and from the Band of Angels. BTW, in a start-up, you never stop trying to raise money until you are profitable. It is a constant issue for every start-up and is the CEO's most important occupation and responsibility.

Where you get your funding can be just as important as getting money at all. I was associated with one Silicon Valley start-up whose largest share-holder was a multi-billion-dollar conglomerate run by a "visionary" individual. Unfortunately, just when the start-up was transitioning into production, the FBI discovered that the true vision of this character was to operate a Ponzi scheme. When the FBI raided his headquarters, all of the assets of the conglomerate were placed in the hands of the court, the monthly funding to the start-up stopped, and 25 people at the start-up were suddenly out of a job. Even the 22 patents from the start-up were held by the court!! Customers were frantic to get more parts, which was impossible. Fortunately, the story does have a happy ending. After 2 years, the start-up CEO was eventually able to purchase the 22 patents from the court, then sold them to a large electronics company, which is now putting the product back into production with most of the original team.

\section{OPERATIONS}

This is one of my pet peeves. Many entrepreneurs make the big mistake of thinking that "the most difficult and most important part of any new product is inventing it". WRONG ! The real magic to create a viable, successful new company is operations. Good operations people have a different mind-set than inventors. Inventors are great at building "one" part. Operations people want to build "thousands" or "millions" of parts which are exactly identical. Good operations people speak about Design for Manufacturability, Design for Test, Cpk (process capability index), SPC (statistical process control), six-sigma, on-time delivery, and are very deliberate and organized. The operations person at SiTime would drive the engineers crazy by worrying about seemingly miniscule process issues. However, the company was moving into markets which required absolutely on-time deliveries and failure rates in the few ppm. Such discipline and rigor in manufacturing is absolutely essential. At Cepheid, I hired an operations person to ramp up production on the SmartCycler. Every month for the following 4 months, he would come to me and say, "I think I can make all the deliveries this month". We had just done an IPO! If we missed our numbers for the quarter, the stock would crash. I fired him and hired an experienced operations person who told me, "I know how to do this. This is what I like to do." She never missed a shipment for the next 4 years.

Similarly, the design of production-ready instrumentation, such as the Cepheid SmartCyler and GeneXpert systems, require experienced industrial design engineers with a focus on design for manufacturability. I have seen SO many "tinker-toy" instruments at start-ups, built by the inventors, which NEVER made it to production. Early at Cepheid, we had 2 competing design concepts for the flag-ship GeneXpert system. One concept was championed by a brilliant $\mathrm{PhD}$ engineer from Berkeley, the other was championed by 2 very experienced, but junior, engineers with no degrees. However, the junior engineers had already designed successfully-manufactured, cost-effective instruments at previous companies. When it came time to make a decision about which design concept to continue into development, I chose the version championed by the 2 junior engineers, despite the fact that either concept would have done the job well. I know this decision would 
inspire the junior engineers to do an outstanding job, using all their DFM experience. Twelve years later, this design represents $95 \%$ of the $\$ 450 \mathrm{M}$ run-rate at Cepheid and its performance is unmatched by any other competitor.

\section{THE EXIT}

Give a lot of thought to your exit from the day you form the company, because I guarantee you, potential investors will ask your thoughts about this. What I mean by "exit" is the point where founders and investors are paid for their stock. Of course, the two most common exits are an IPO, and an acquisition. Be realistic and truthful to yourself during this analysis. Besides the fact that an IPO for a hardware company is extremely rare, the time it can take to achieve an IPO can be extremely long. InvenSense took 8 years. SiTime has entered its $9^{\text {th }}$ year - no IPO yet. While Cepheid did its IPO in 2000 (its $4^{\text {th }}$ year) this was during the unusual dotcom boom when IPOs were the norm. Those days are long gone. So, maintain in your mind the option of an acquisition. Encourage and continually reinforce relationships with potential acquirers. In early 1990, NovaSensor was having trouble raising needed capital from investors. However, we knew that the MEMS products we were shipping and the technology we had developed was valuable. One of my partners, Janusz Bryzek, had a lot of contacts (his network) in the nascent MEMS industry. He knew of a company, Lucas Industries, which had tried and failed to purchase a competitor pressure sensor manufacturer. He contacted Lucas and they immediately engaged with us to acquire NovaSensor. The sale was completed in May of 1990, to the benefit of the founders.

Even though an acquisition is statistically much more likely than an IPO, your company is $\mathrm{MUCH}$ more valuable to the acquirer if it is organized and operated as a professional, standalone company, ready for an IPO. For this reason, quality systems, $\mathrm{HR}$, finance, legal, operations, all need to be established and maintained at the highest possible levels, even if you are planning for an acquisition. Get those experienced business people in place.

\section{FINAL THOUGHTS}

While I have always thought of myself as a research person, I am passionate that the fruits of my research become products which help people in some way. This is the reason I originally began my career as an entrepreneur. However, a start-up is not for the faint of heart. Be prepared, it is a huge emotional roller-coaster ride, with enormous highs and lows. The pressures and the uncertainties can be intense.

If you want to be involved with start-up companies, your network is your best friend. Don't be shy about asking accomplished entrepreneurs for advice and mentoring. Even a modestly successful start-up company is incredibly exhilarating and satisfying. Remember, for investors, the Team is first, the Market is second, and the Technology is third. Even though Series A financings are very difficult to achieve today, there are still MANY opportunities for start-up companies, especially from the angel community. Also, the proliferation of incubators and hardware development labs/companies is a huge benefit for new entrepreneurs. Go ahead, don't be afraid to change the world !! 